\title{
Cracking and delamination of metal organic vapour deposited alumina and silica films
}

\author{
V. A. C. Haanappel, H. D. van Corbach, T. Fransen* and P. J. Gellings \\ Department of Chemical Technology, University of Twente, P.O. Box 217, Enschede (Netherlands)
}

(Received October 8, 1992; in revised form February 5, 1993)

\begin{abstract}
Amorphous alumina and silica films were deposited on AISI 304 by thermal decomposition at atmospheric pressure of aluminium-tri-sec-butoxide and di-acetoxy-di-tertiary-butoxide-silane respectively. Above a critical coating thickness of the oxide films, cracking and delamination occurred during the deposition process. These were due to intrinsic rather than to thermal stresses. Cracking and delamination do not occur simultaneously. The fracture toughness of the film, the substrate and the interface is an important factor. After delamination along the substrate-film interface, the films curled to scrolls, indicating stress. A complete explanation of the stress gradient formed in the film during the deposition process is not yet available.
\end{abstract}

\section{Introduction}

Thin oxide films are used for many applications, for example electronic devices, cutting tools, optical lenses and corrosion protection. For corrosion protection, not only the specific chemical properties of the deposited material relevant to resistance to high temperature corrosion, but also the mechanical properties are of great importance in the protection of the substrate. Protection against corrosion is provided only if mechanical properties such as the adhesion strength to the substrate are good, because otherwise the films tend to spall or break away.

Thin films deposited by metal organic chemical vapour deposition (MOCVD) are in general subject to residual stresses [1-21]. Large residual stresses can cause cracking and failure of thin ceramic films. Susceptibility to cracking and delamination of deposited films is a function of several parameters, such as material properties and process parameters of the MOCVD process.

In this study, experiments were performed to obtain some understanding of the cracking and delamination mechanism of the deposited films associated with the mechanical aspects. The experiments were performed using AISI 304 on which $\mathrm{SiO}_{2}$ and $\mathrm{Al}_{2} \mathrm{O}_{3}$ were

\footnotetext{
*Author to whom correspondence should be addressed.
}

deposited. It was found that cracking and delamination of the coating occurred during the deposition process, therefore the failure of the films was predominantly due to stresses formed during film growth, and not those formed on cooling (thermal stresses).

\section{Experimental details}

\subsection{Deposition of $\mathrm{Al}_{2} \mathrm{O}_{3}$}

Thin films of alumina were deposited by thermal decomposition of aluminium-tri-sec-butoxide (ATSB) on AISI 304. The AISI 304 specimens were cut from an electropolished metal sheet and ultrasonically cleaned in hexane and ethanol prior to coating.

A schematic view of the experimental apparatus is shown in Fig. 1. The vapours were transported to the vertical furnace (with a quartz tube) by bubbling nitrogen through the precursor, heated by silicon oil. This gas stream was subsequently mixed with a diluent gas flow of nitrogen to obtain the desired gas-phase concentration. The specimens were attached to a ceramic tube with a thermocouple on the inside in order to measure the substrate temperature and control the furnace temperature.

The standard conditions for a film growth of $0.8 \mathrm{mg}$ $\mathrm{cm}^{-2} \mathrm{~h}^{-1}\left(2 \mu \mathrm{m} \mathrm{h}^{-1}\right)$ were: silicon oil bath with ATSB, $138^{\circ} \mathrm{C}$; carrier gas flow $\left(\mathrm{N}_{2}\right), 1300 \mathrm{ml} \mathrm{min}^{-1}$ (STP);

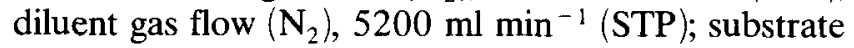
temperature, $330^{\circ} \mathrm{C}$. 


\subsection{Deposition of $\mathrm{SiO}_{2}$}

Thin silica films were produced by the decomposition of di-acetoxy-di-tertiary-butoxide-silane (DADBS) on AISI 304 and Incoloy $800 \mathrm{H}$. The deposition set-up (see Fig. 1) was the same as that for alumina. The deposition parameters used for a film growth of 0.75 $\mathrm{mg} \mathrm{cm}{ }^{-2} \mathrm{~h}^{-1}\left(3 \mu \mathrm{m} \mathrm{h}^{-1}\right)$ were: silicon oil bath with

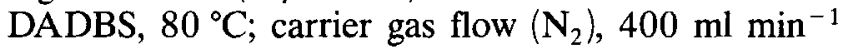
(STP); diluent gas flow $\left(\mathrm{N}_{2}\right), 400 \mathrm{ml} \mathrm{\textrm {min } ^ { - 1 }}$ (STP); substrate temperature, $560^{\circ} \mathrm{C}$.

\subsection{Analysis}

The morphology and composition of the films formed on the samples were investigated by means of optical microscopy, scanning electron microscopy (SEM) (JEOL M $35 \mathrm{CF}$ ) equipped with an EDX analysis system (Kevex), and Auger electron spectroscopy (AES) (Perkin Elmer PHI 600). The deposition rate of the films on the metallic substrates was determined by weighing the samples before and after the deposition. The thickness of the coatings was calculated by using the bulk densities of alumina and silica, $4.0 \times 10^{3}$ and $2.5 \times 10^{3} \mathrm{~kg} \mathrm{~m}^{-3}$, assuming that the bulk values can also be used for these thin films.

\section{Results}

\subsection{SEM observations}

During the deposition of thin alumina and silica films on AISI 304, the films spalled at the critical thicknesses of $1 \mu \mathrm{m}$ and $1.5 \mu \mathrm{m}$ respectively. Cracking and

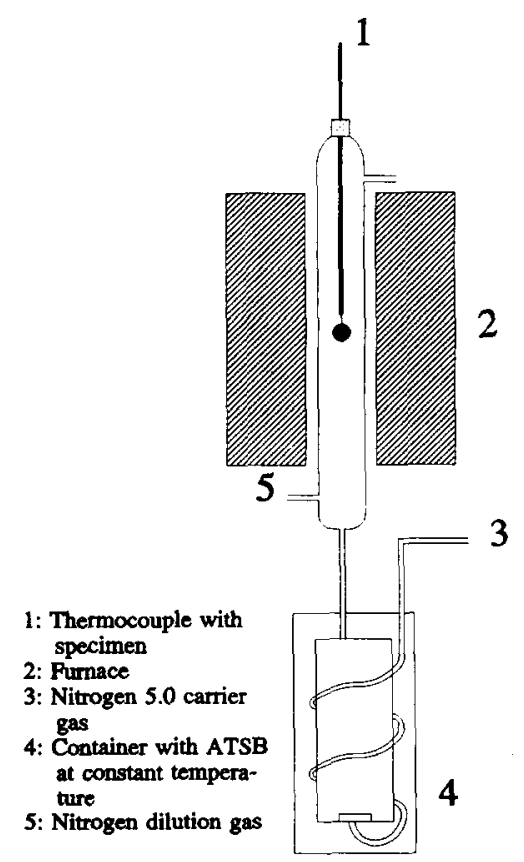

Fig. 1. Schematic view of the MOCVD equipment. delamination of the films occurring during the deposition was confirmed by observations with SEM and EDX. Figures 2(a) and 2(b) show the delamination of the alumina film after deposition times of $45 \mathrm{~min}$ and $60 \mathrm{~min}$ respectively (film growth $2 \mu \mathrm{m} \mathrm{h}^{-1}$ ). These observations clearly show that cracking and delamination take place during the deposition process, because deposition on the cracked edges and corners is more pronounced, as shown by the round corners after longer deposition times. The same phenomena were observed with $\mathrm{SiO}_{2}$ coatings. Figures 3(a) and 3(b) show the delaminated silica film deposited for $35 \mathrm{~min}$ and $70 \mathrm{~min}$ respectively (film growth: $3 \mu \mathrm{m} \mathrm{h}^{-1}$ ). Beneath the curled and spalled alumina film, new alumina was detected. This was more pronounced after longer deposition times. At the sites where delamination of the film was initiated, almost no alumina could be detected, indicating delamination after interfacial cracking. For a coating thickness less than the critical thickness, only cracking of the alumina film (thickness $0.8 \mu \mathrm{m}$ ) was observed (Fig. 4). At this stage no decohesion could be found.
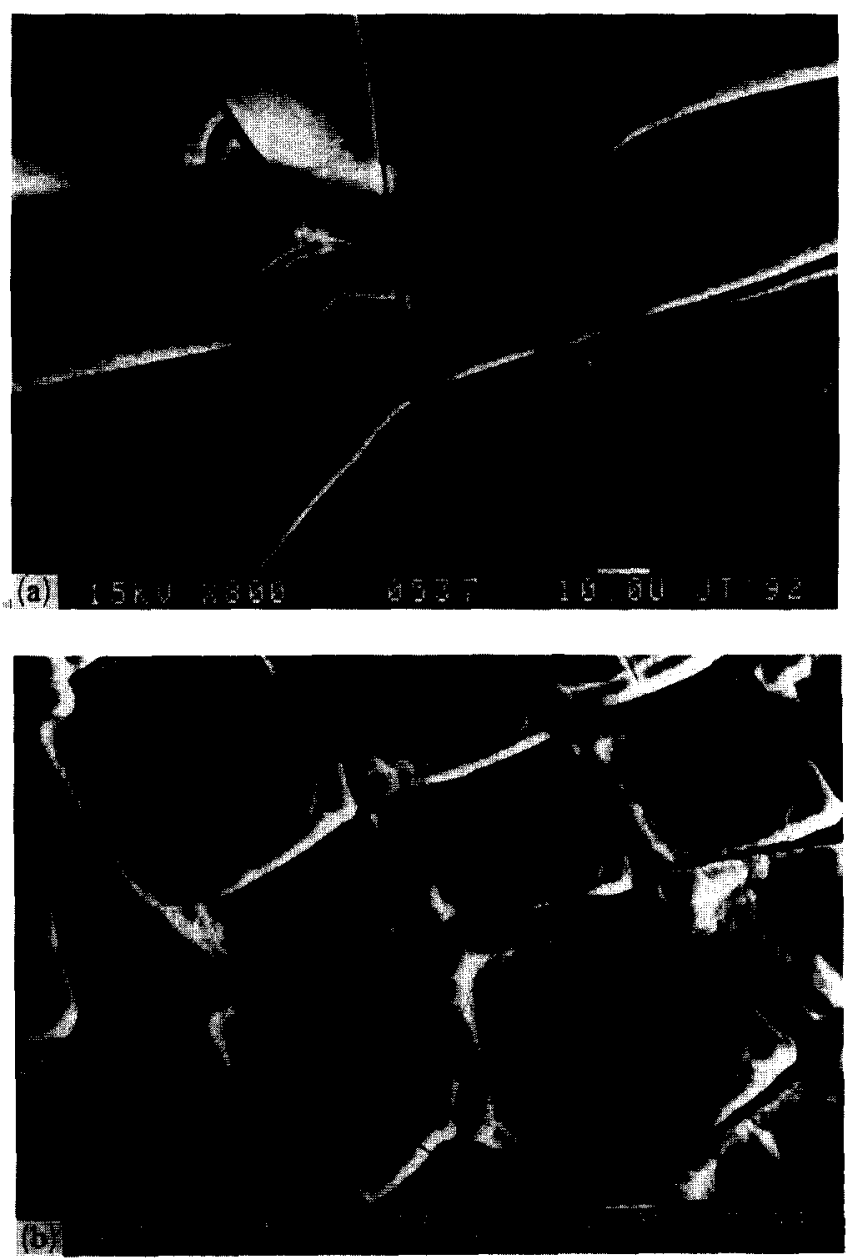

Fig. 2. Delaminated $\mathrm{Al}_{2} \mathrm{O}_{3}$ film on AISI 304: deposition time (a) $45 \mathrm{~min}$, (b) $60 \mathrm{~min}$. 

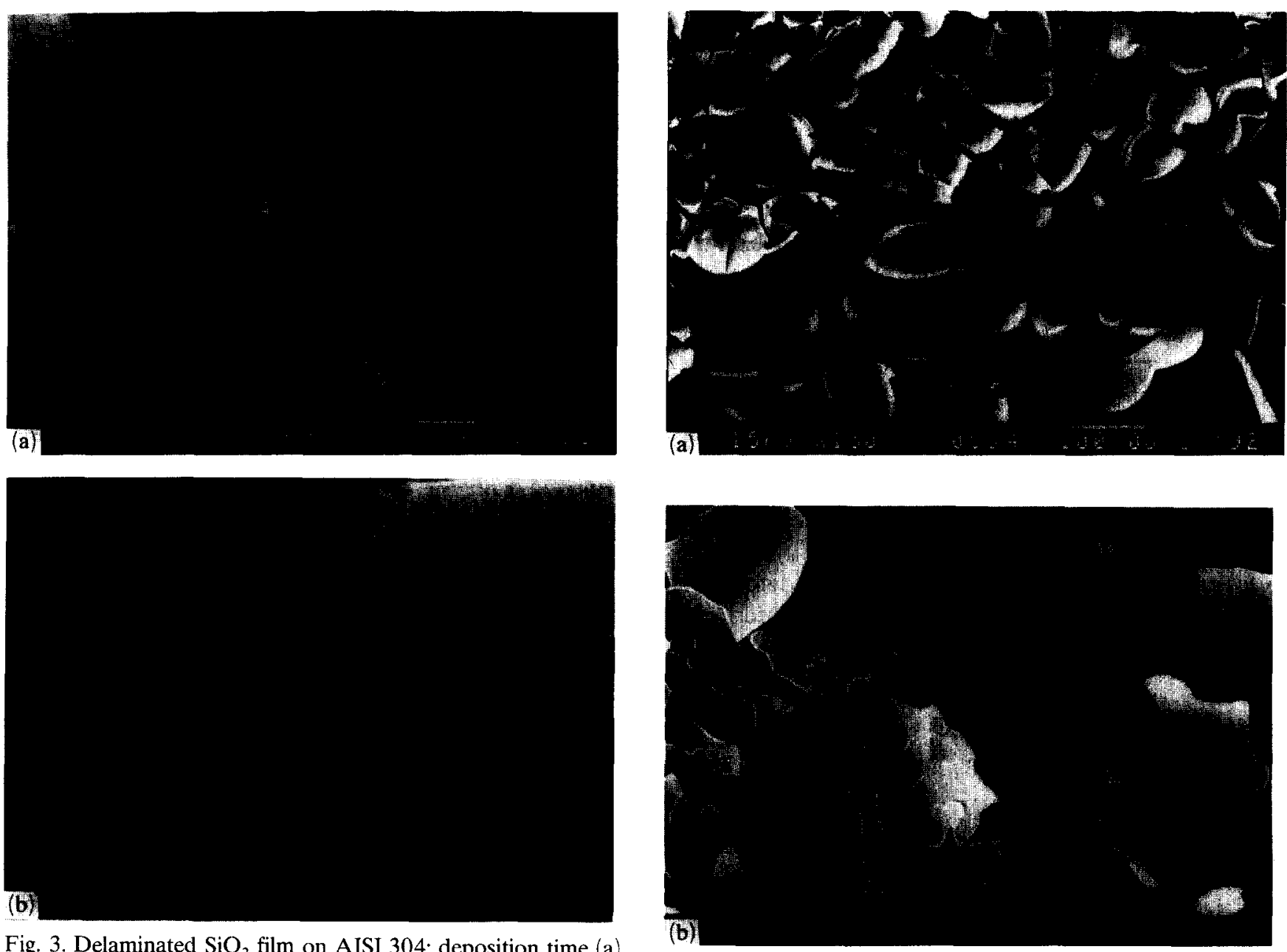

Fig. 3. Delaminated $\mathrm{SiO}_{2}$ film on AISI 304: deposition time (a) $35 \mathrm{~min}$, (b) $70 \mathrm{~min}$.

Fig. 5. (a) Delaminated $\mathrm{Al}_{2} \mathrm{O}_{3}$ film on AISI 304 (deposition time 60 min; (b) delaminated $\mathrm{SiO}_{2}$ film on AISI 304 (deposition time $35 \mathrm{~min}$ ).

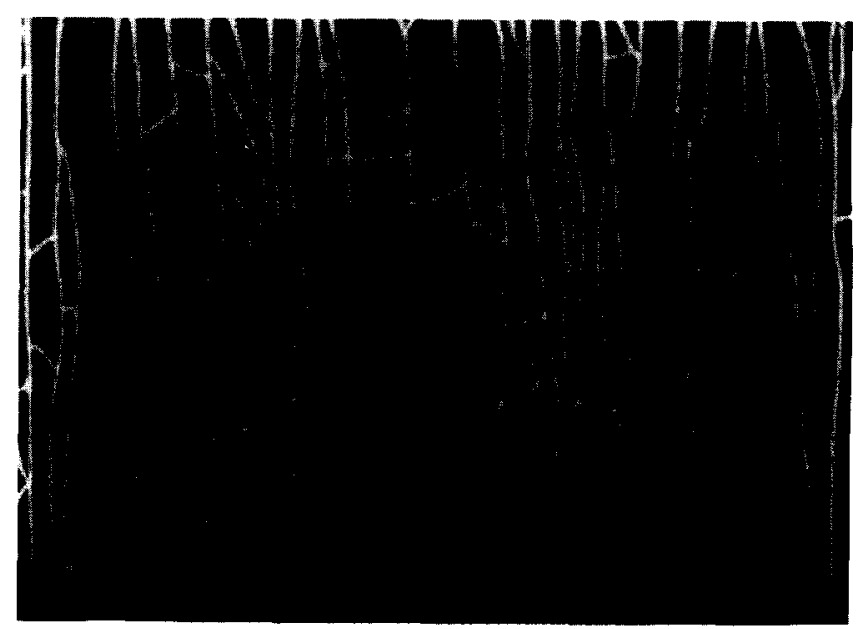

Fig. 4. SEM image showing cracks of a $0.8 \mu \mathrm{m} \mathrm{Al}_{2} \mathrm{O}_{3}$ film on AISI 304.

Figures 5(a) and 5(b) show spallation and delamination of alumina and silica films. Spallation during the deposition process was confirmed by a discontinuous increase of the deposition rate, expressed as milligrams

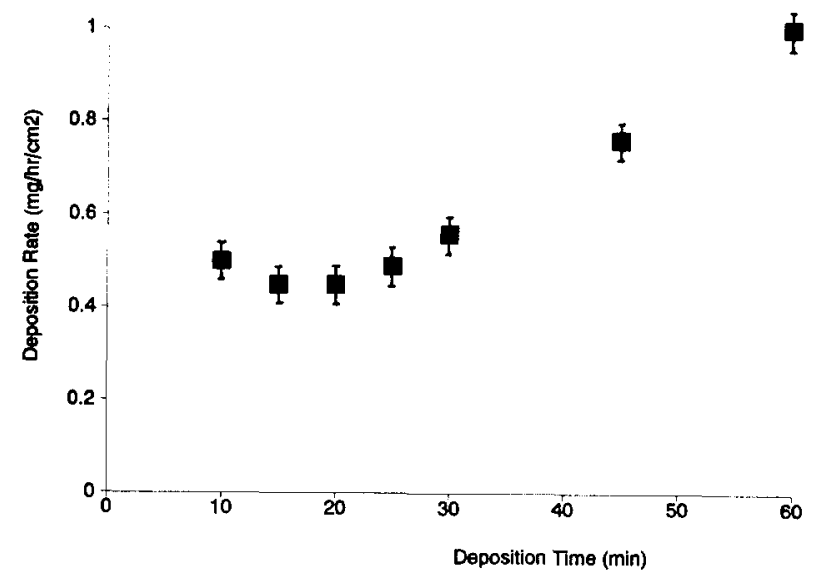

Fig. 6. Deposition rate of $\mathrm{Al}_{2} \mathrm{O}_{3}$ (milligrams per hour per unit substrate surface) as a function of the deposition time (layer thickness was determined by weighing the sample before and after the deposition process). 
per hour per unit substrate surface (see Fig. 6). This can be explained by an increased surface area after cracking and delamination (curling away of the film from the substrate).

The best way to prove absolutely the assumption on cracking and delamination during the deposition process would be to observe the film at high temperatures during deposition prior to cooling, for example by optical means. In our case the experimental set-up was not equipped with an in situ optical microscope or another suitable instrument. Only "after-deposition" results were thus available for the cracking-duringdeposition interpretation.

\subsection{AES analyses}

Auger depth profiles were obtained for samples deposited with alumina at $330{ }^{\circ} \mathrm{C}$ (thickness 0.2 and $0.8 \mu \mathrm{m})$. The profiles are shown in Figs. 7(a) and 7(b). No carbon or other contaminants could be detected in the oxide layer, either in the coating or at the interface.
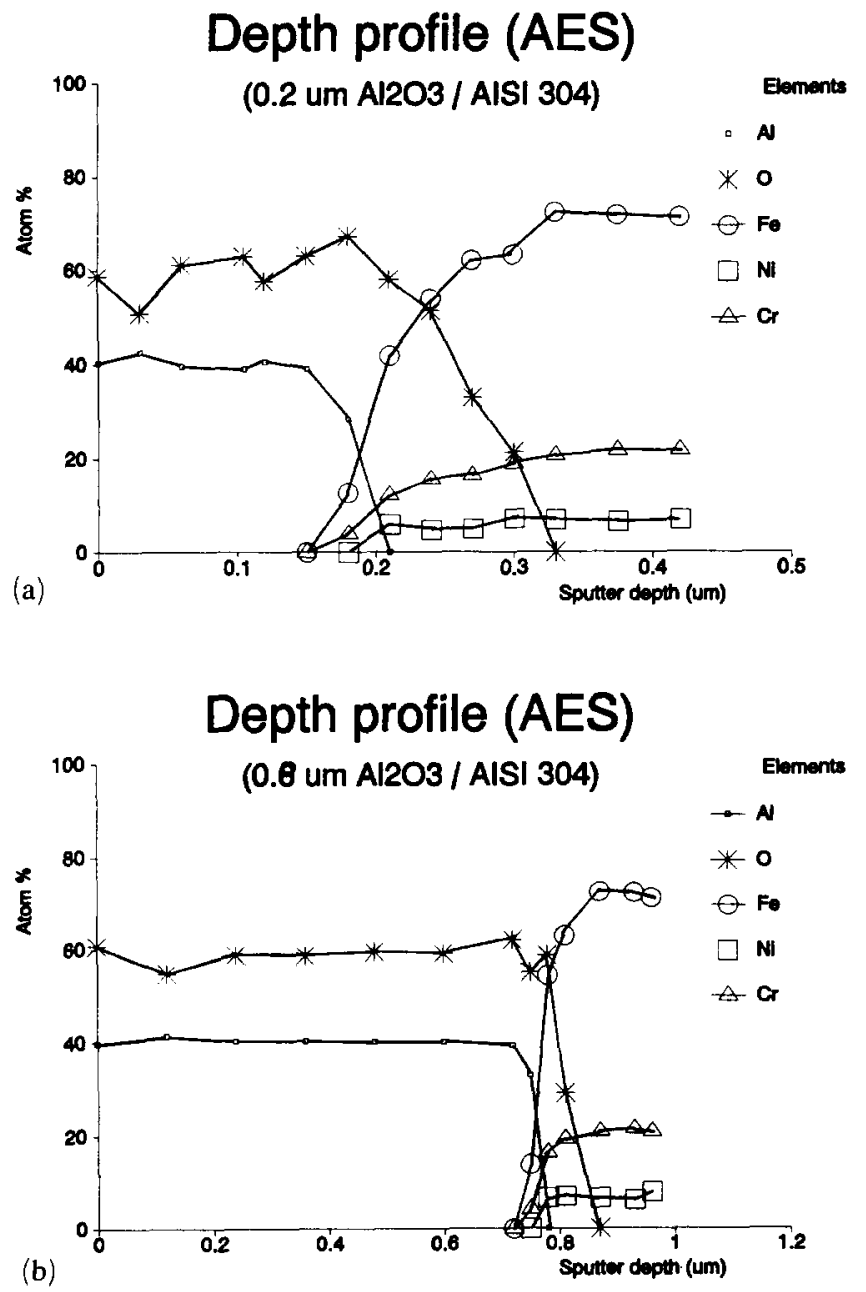

Fig. 7. AES depth profile of the $\mathrm{Al}_{2} \mathrm{O}_{3}$ film on AISI 304: film thickness (a) $0.2 \mu \mathrm{m}$, (b) $0.8 \mu \mathrm{m}$.
The delaminated alumina coating was investigated by scanning Auger microscopy. Spectra at different parts of the surface are shown in Fig. 8. Three positions were analysed: $(a)$ the surface of the alumina film at the gas side, $(b)$ the surface of the alumina film near the film-substrate interface and $(c)$ the surface of the substrate after delamination of the alumina scale. At position $(a)$ only aluminium and oxygen are detected, at position $(b)$ aluminium, oxygen and perhaps a very small amount of iron are detected, at position $(c)$ aluminium, oxygen and iron are detected. Figure 9 shows an SEM image of delaminated alumina: it is clear that no substrate cracking (decohesion along the interface) occurred, because if it had, depressed regions would be found where the metallic substrate had been removed with the film. From these observations it is clear that delamination of the alumina films takes place by interfacial cracking.

\section{Discussion}

Thin oxide films applied by MOCVD suffer in general from thermal and intrinsic (growth) stresses, according to

$$
\sigma_{\text {total }}=\sigma_{\text {intrinsic }}+\sigma_{\text {thermal }}
$$

SEM and AES analyses indicate that cracking and decohesion of the silica and alumina films, after passing a critical thickness $h_{\mathrm{c}}$, took place during the deposition process and not during cooling. Thus, $\sigma_{\text {intrinsic }}$ was mainly responsible for crack formation and film delamination. The thermal stress, $\sigma_{\text {thermal }}$ (a function only of thermal expansion coefficients) cannot account for this critical thickness [1], because the deposition is an isothermal process.

In order to understand the fracture mechanism of superficially applied thin oxide films involving crack formation, crack propagation and film delamination, it is important to know the fracture toughness $\Gamma$ of the materials. $\mathrm{Hu}$ [2] distinguishes three different fracture toughnesses: those of the film $\left(\Gamma_{\text {film }}\right)$, of the interface $\left(\Gamma_{\text {interface }}\right)$ and of the substrate $\left(\Gamma_{\text {substrate }}\right)$. It was found that if ductile substrates and brittle films are used, the cracks are prevented from penetrating the substrate. This means that $\Gamma_{\text {film }}$ and $\Gamma_{\text {interface }}$ are the most important material properties to describe the cracking and delamination behaviour. Hu found that if $\Gamma_{\text {film }} /$ $\Gamma_{\text {interface }}>4$, film cracking and delamination occurred simultaneously. When brittle substrates are used the fracture toughness $\Gamma_{\text {substrate }}$ is also important. The fracture toughnesses for some materials are given in Table 1 (note that these are bulk values). Relatively thick alumina $(>1.0 \mu \mathrm{m})$ and silica films $(>1.5 \mu \mathrm{m})$, deposited on AISI 304, were found to delaminate only 

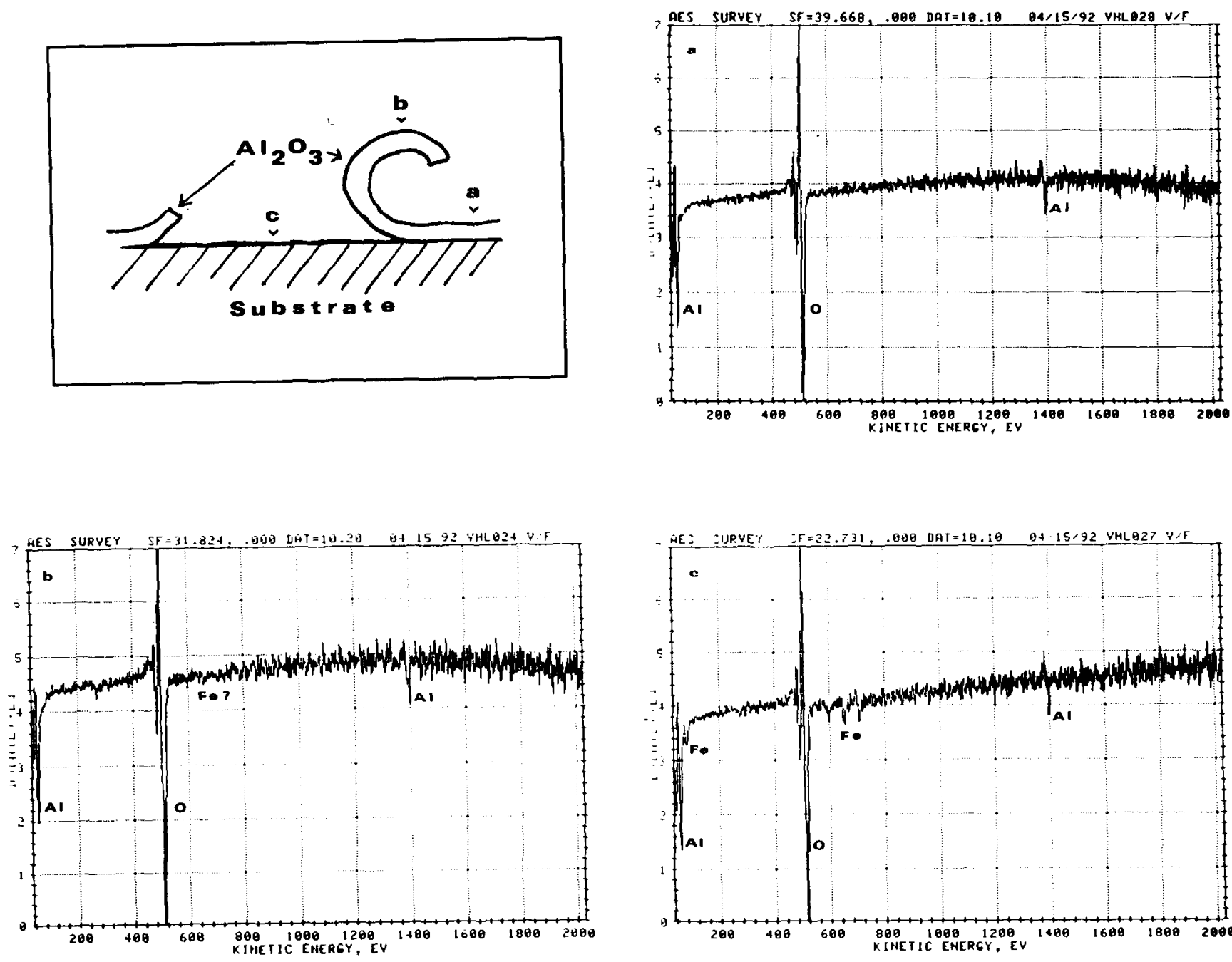

Fig. 8. AES survey spectra for different positions of a delaminated $\mathrm{Al}_{2} \mathrm{O}_{3}$ film.

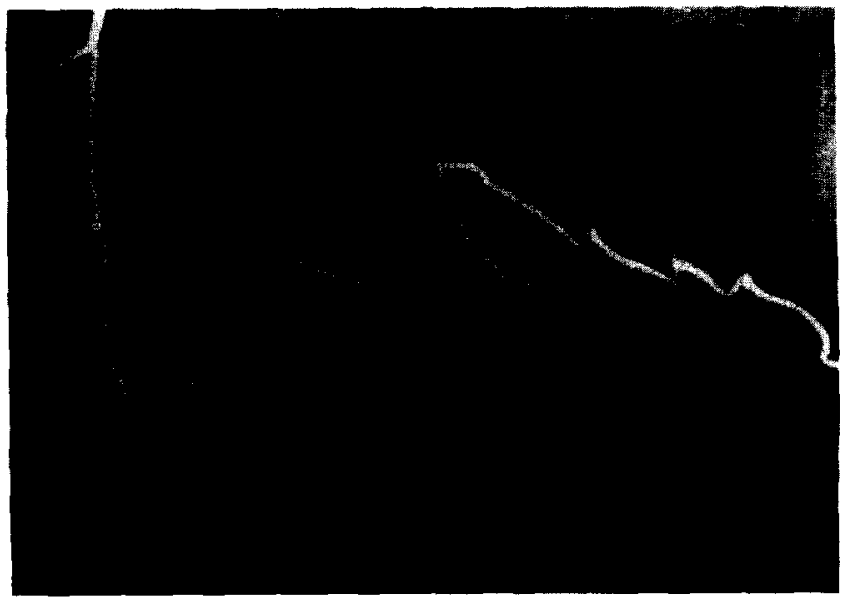

Fig. 9. SEM image of delaminated $\mathrm{Al}_{2} \mathrm{O}_{3}$ film on AISI 304.

by interfacial cracking, without substrate cracking. This is probably due to the relatively high fracture toughness of the substrate and the inferior adherence of the film on the substrate. In this case $\Gamma_{\text {film }}$ and $\Gamma_{\text {interface }}$ are considered to be the factors dominating the fracture mechanism. Furthermore, it was observed that for alumina on AISI 304 crack formation preceded delamination (see Figs. 4 and $5(\mathrm{a})$ ). It is therefore assumed that in these cases film cracking and film decohesion are not simultaneous processes, thus $\Gamma_{\text {film }} /$ $\Gamma_{\text {interface }}<4$.

If $\Gamma_{\text {alumina }}=2 \mathrm{MPa} \mathrm{m}^{1 / 2}$, then $\Gamma_{\text {interface }}>0.5 \mathrm{MPa} \mathrm{m}^{1 / 2}$. Because no substrate cracking occurred, $\Gamma_{\text {substrate }} /$ $\Gamma_{\text {interface }}>4$. With $\Gamma_{\text {substrate }}=40 \mathrm{MPa} \mathrm{m}{ }^{1 / 2}, \Gamma_{\text {interface }}<10$ $\mathrm{MPa} \mathrm{m}^{1 / 2}$. This in turn can lead to a rough estimate of fracture toughness of the interface $\Gamma_{\text {interface }}$ of $0.5-10$ MPa $\mathrm{m}^{1 / 2}$.

The curvature of the spalled films indicates a stress gradient. With regard to the detached and curled film, the intrinsic stress (no adhesion between the film and the substrate means no thermal stress) at distance $s$ from the neutral plane can be estimated from

$\sigma_{\text {intrinsic }}=E_{\mathrm{f}} s / R$ 
where $E_{\mathrm{f}}$ is the Young's modulus of the film, $R$ is the curvature of the detached film and $s$ is the distance from the neutral plane (see Fig. 10).

At known values of $E_{\mathrm{f}}, s$ and $R$ are known (see Table 1) and the stress parallel to the interface can be calculated. This means that the maximum stress at the outside of the film and at the substrate-film interface, in this case for $s=($ coating thickness $) / 2$, can be determined. The total internal stress can be calculated from eqn. (2). With typical values of $s=0.5 \mu \mathrm{m}$ and $R=$ $50 \mu \mathrm{m}$ (see Fig. 5(a)), the internal stress for $\mathrm{Al}_{2} \mathrm{O}_{3}$-AISI 304 is $\sim 3.8 \times 10^{9} \mathrm{~N} \mathrm{~m}^{-2}$.

The contribution of the thermal stress to the total internal stress can be determined if it is assumed that the coating, after cooling to room temperature, shows no decohesion from the metallic substrate. Consider the thermal expansion coefficients $\alpha\left(\mathrm{Al}_{2} \mathrm{O}_{3}\right)=8 \times 10^{-6}$ $\mathrm{K}^{-1}$ and $\alpha\left(\right.$ steel) $=12 \times 10^{-6} \mathrm{~K}^{-1}$ (assuming that the bulk values can also be used here) and the difference between deposition temperature and room temperature $\Delta T=300 \mathrm{~K}$. The thermally induced part of the stress in alumina on steel can be calculated from the simplified equation

$$
\sigma_{\text {thermal }}=E_{\mathrm{f}} \Delta T \Delta \alpha
$$

where $\Delta T$ is the difference between deposition and actual temperature and $\Delta \alpha$ is the difference between thermal expansion coefficients.

For the $\mathrm{Al}_{2} \mathrm{O}_{3}$-steel combination, the calculated thermal stress component is $\sim 4.6 \times 10^{8} \mathrm{~N} \mathrm{~m}^{-2}$. Comparing the values for the thermal and total internal stress, it is clear that the thermally induced part of the stress is almost negligible.

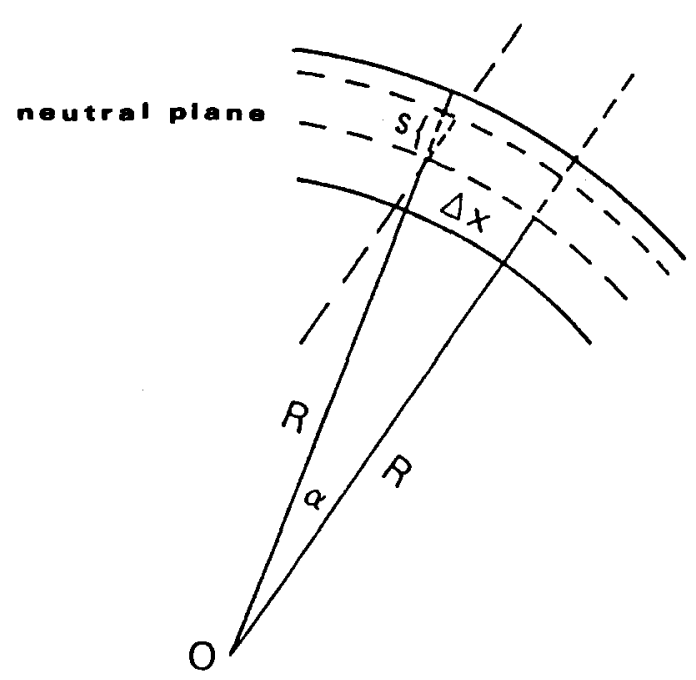

Fig. 10. Schematic view of a cross-section of a detached and curled oxide film.
The origin of intrinsic stresses is unclear. Morssinkhof [7] reported that a large internal stress can be explained by the presence of hydroxide groups in the oxide scale. Tucker [8] suggested that the residual stress increased linearly with coating thickness, but an exact mechanism explaining the influence is not yet available.

To increase the protectiveness of coatings against high temperature corrosion, a crack-free oxide film without delamination should be produced. This means that the adhesion of the deposited films should increase and/or the intrinsic stress should be reduced. Effects influencing the adhesion strength include the formation of an intermediate oxide layer between the coating and the metal, and a modification of the bonding at the metal-oxide layer [6]. Sigler [9] reported that a low sulphur concentration in an alloy is detrimental to the adherence of alumina. This influence can be eliminated by the addition of reactive elements such as yttrium to the alumina to remove sulphur from the interface. If elements such as $\mathrm{Ti}$ and $\mathrm{Zr}$ are added to the alumina the adherence increases, due to a strong interaction of these elements with $\mathrm{C}$ or $\mathrm{N}$. This was also found by Yoshitake et al. [10] and Tosa et al. [11], who found that precipitation of $\mathrm{TiC}$ in $321,14 \mathrm{C}$ and $47 \mathrm{C}$ steels results in strong adhesion of the $\mathrm{Al}_{2} \mathrm{O}_{3}$.

Methods to reduce the internal stress include a lowering of the deposition rate, a changing of substrate material, the incorporation of other elements such as silicon oxide and magnesium oxide in the oxide lattice, and the addition of oxygen or water to the gas stream saturated with the precursor. Further research will soon be performed to obtain a crack-free oxide-substrate combination with optimum properties.

\section{Conclusions}

Cracking and delamination of vapour-deposited alumina and silica films on AISI 304 took place nonsimultaneously during the deposition process, indicating that only the growth (intrinsic) stress is responsible for this behaviour. An exact mechanism to explain the stress is not yet available.

TABLE 1. Material properties

\begin{tabular}{lcc}
\hline Material & $\begin{array}{l}\text { Young's modulus } E \\
(\mathrm{GPa})\end{array}$ & $\begin{array}{l}\text { Fracture toughness } \Gamma \\
\left(\mathrm{MPa} \mathrm{m}^{1 / 2}\right)\end{array}$ \\
\hline $\mathrm{SiO}_{2}$ & $80-140$ & $0.5-1.0$ \\
$\mathrm{Al}_{2} \mathrm{O}_{3}$ & 380 & $1.4-4.2$ \\
$\mathrm{Cr}_{2} \mathrm{O}_{3}$ & $>100$ & 3.9 \\
$\mathrm{ZrO}_{2}$ & $50-200$ & $1.3-9^{\mathrm{a}}$ \\
Metals-alloys & $100-300$ & $40-100$ \\
\hline
\end{tabular}

astabilized $\mathrm{ZrO}_{2}$. 


\section{Acknowledgments}

This research was supported by the Innovative Research Programme on Technical Ceramics (IOP-TK) with the financial aid of the Dutch Ministry of Economic Affairs. The authors thank A. v.d. Berg (University of Twente) for the scanning Auger measurements, J. Wassens (University of Twente) for technical assistance and G. Verspui, K. Visser and F. Sanders (Philips, Eindhoven) for valuable discussions.

\section{References}

1 V. A. C. Haanappel, H. D. van Corbach, R. Hofman, T. Fransen and P. J. Gellings, Proc. Conf. on High Temperature Corrosion, Les Embiez, France, in the press.

2 M. S. Hu, in J. C. Bravman, W. D. Nix, D. M. Barnett and D. A. Smith (eds.), Mater. Res. Soc. Symp. Proc. 130, Materials Research Society, Pittsburgh, PA, 1988, p. 213.

3 S. Shinzato, T. Sumomogi, S. Kofune and K. Kuwahara, Thin Solid Films, 97(1982) 333.

4 Th. Roth, K. H. Kloos and F. Broszeit, Thin Solid Films, 153 (1987) 123.

5 W. A. Bryant, J. Mater. Sci. 2 (1977) 1285.

6 K. L. Luthra and C. L. Briant, Oxid. Met., $26(1986) 397$.
7 R. W. J. Morssinkhof, PhD Thesis, University of Twente, 1991.

8 R. C. Tucker, J. Vac. Sci. Technol., II (1974) 725.

9 R. D. Sigler, Oxid. Met., 32(1989) 337.

10 W. Yoshitake, M. Tosa and K. Yoshihara, Thin Solid Films, $172(1989) 35$.

11 M. Tosa, Y. Ikeda and K. Yoshihara, Thin Solid Films, 177 (1989) 107.

12 R. M. Fisher, J. Z. Duan and J. B. Liu, in M. F. Doerner, W. C. Oliver, G. M. Pharr and F. R. Brotzen (eds.), Mater. Res. Soc. Symp. Proc. 188, Materials Research Society, Pittsburgh, PA, 1990, p. 257.

13 M. S. Hu, M. D. Thouless and A. G. Evans, Acta Metall., 36 (1988) 1301.

14 A. G. Evans, G. B. Crumley and R. E. Demaray, Oxid. Met., $20(1983) 193$.

15 A. Bartlett, A. G. Evans and M. Ruhle, Acta Metall. Mater., 39(1991) 1579.

16 M. D. Drory and A. G. Evans, J. Am. Ceram. Soc., 73(1990) 634.

17 S. B. Desu, in T. M. Besmann and B. M. Gallois (eds.), Mater. Res. Soc. Symp. Proc. 168, Materials Research Society, Pittsburgh, PA, 1989, p. 221.

18 I. E. Reimanis, B. J. Dalgleish and A. G. Evans, Acta Metall. Mater., 39(1991) 3133.

19 B. J. Dalgleish, M. C. Lu and A. G. Evans, Acta Metall., 36 (1988) 2029.

20 Z. E. Majid and M. Lambertin, Oxid. Met., 27(1987) 333.

21 S. B. Desu, Jpn. J. Appl. Phys, 30 (1991) L2123. 